\title{
Enhanced Recovery After Cesarean: Current and Emerging Trends
}

\author{
Kishan Patel ${ }^{1} \cdot$ Mark Zakowski $^{1}$ (i) \\ Accepted: 15 February 2021 / Published online: 2 March 2021 \\ (C) The Author(s), under exclusive licence to Springer Science+Business Media, LLC part of Springer Nature 2021
}

\begin{abstract}
Purpose of Review What are the latest enhanced recovery elements for cesarean delivery?

Recent Findings Enhanced recovery after cesarean delivery (ERAC) provides an evidenced-based system to improve maternal outcomes, functional recovery, maternal-infant bonding, and patient experience. Postsurgical recovery has evolved from a onedimensional pain score to a holistic multidimensional approach emphasizing faster functional recovery. ERAC involves multidisciplinary efforts of the anesthesiologist, obstetrician, nursing, hospital, and patient. Components of ERAC include preoperative patient education, limited fasting, carbohydrate load, limiting opioids intra- and postoperatively, using scheduled nonopioid analgesics and supplementing with advanced therapies for women at higher risk for pain. ERAC protocols reduce opioid consumption, reduce length of stay, and improve maternal and neonatal outcomes.

Summary Implementing ERAC standardized care will likely be the most important change you can make in your practice to improve outcomes, improve quality care, help address racial disparities, and minimize opioid exposure and potential for addiction.
\end{abstract}

Keywords Cesarean delivery $\cdot$ Enhanced recovery $\cdot$ Racial disparity $\cdot$ Opioid use disorder $\cdot$ Maternal outcomes $\cdot$ Length of stay

\section{Introduction}

Enhanced recovery after cesarean (ERAC) provides an evidenced-based system to improve maternal outcomes, functional recovery, maternal-infant bonding, and patient experience. ERAC involves the multidisciplinary team efforts of the anesthesiologist, obstetrician, nursing, hospital, and patient. Cesarean delivery $(\mathrm{CD})$ is the most common surgery in the USA, with a $32 \%$ cesarean rate that involves 1.2 million women yearly [1] similar to the rate in many developed countries. The global burden of obstetrical surgical recovery includes approximately 140,000,000 births annually [2] with an estimated 23\% global cesarean rate [3]. Hospital length of stay (LOS) for CD has large variations at the provider and facility level [4]. Chronic postsurgical pain for CD affects up to $11 \%$ of women 1 year later with nearly $10 \%$ having severe pain [3, $5,6]$. ERAC aims to standardize the perioperative care of the

This article is part of the Topical Collection on Obstetric Anesthesia

Mark Zakowski

Mark.Zakowski@cshs.org

1 Department of Anesthesiology, Cedars-Sinai Medical Center, 8700 Beverly Blvd \#8211, Los Angeles, CA 90048, USA peripartum patient and helps improve maternal and neonatal outcomes $[7,8,9 \cdot \bullet]$. Current and emerging ERAC and pain relief strategies will be discussed in this article.

Chronic pain, which often starts as acute pain, has become a major public health problem affecting 20.4\% adults in 2019 [10]. Women have more chronic pain $(21.7 \%$ vs. $19 \%, P<$ $0.05)$ and more high-impact chronic pain $(8.5 \%$ vs. $6.3 \%, P<$ $.05)$ than men, even affecting $9-15 \%$ of $18-44$ year olds [10]. Previous studies have shown an association between higher pain scores after delivery with a higher incidence of postpartum depression and development of chronic pain $[3,6,11 \bullet$, 12•]. Higher pain postdelivery has been associated with lower rates of breastfeeding as well as a higher incidence of postpartum depression and chronic pain [13]. Every $10 \%$ increase in severe pain postoperatively was associated with a $30 \%$ increase in chronic pain 1 year later [14]. Higher analgesic consumption in the first $48 \mathrm{~h}$ also has been linked to development of chronic pain [15]. Healthcare disparities in pain and the treatment of pain exist as well [16].

Postsurgical recovery has evolved from focusing on a onedimensional goal of a visual analog scale (VAS) pain score $\leq 3 / 10$ to a more holistic multidimensional approach. The fundamental goal of experiencing less pain not only reduces an individual's suffering but also improves functional recovery with faster return to the activities of daily living, including 
maternal-infant bonding, returning home, and higher satisfaction. ERAC uses an interdisciplinary approach requiring the enrollment of the patient (and her support system), anesthesiology, obstetrics, pediatrics, nursing, lactation specialists, and the hospital. Pregnant women and their partners must be educated prior to coming into the hospital to align expectations of what to do (e.g., clear liquids/carbohydrate load $2 \mathrm{~h}$ prior to surgery) and for postoperative physical activity. The intraoperative anesthetic and postoperative pain medications are the easiest ERAC components to change for the anesthesiologist. The postoperative course requires more nursing involvement on the first 1-2 days to help mobilize the mother.

Implementing ERAC standardized care will likely be the most important change you can do in your practice to improve maternal outcomes, improve quality care, help address racial disparities, and minimize opioid exposure and addiction.

\section{Preoperative Elements}

Key ERAC preoperative elements include patient education, limiting fasting intervals, and carbohydrate loading.

\section{Patient Education}

Preoperative education prior to the day of surgery is important to engage the patient, manage expectations, reduce anxiety, and help improve patient compliance with ERAC protocols. Many handouts and tools exist, including examples available in the Society for Obstetric Anesthesia and Perinatology (SOAP) ERAC toolkit (www.soap.org). A 2015 UK study found a simple patient information leaflet led to wider patient acceptance of early discharge and a higher rate of earlier discharges even before implementation of other ERAC components [17••]. Patient engagement and shareddecision making may start preoperatively and improve satisfaction and reduce opioid prescriptions [18].

\section{Limiting NPO Interval and Carbohydrate Loading}

The American Society of Anesthesiologists (ASA) guidelines recommend surgical fasting (NPO) for fatty solids $8 \mathrm{~h}$ prior, a light meal $6 \mathrm{~h}$ prior, and clear liquids $2 \mathrm{~h}$ prior to surgery to reduce aspiration risk [19]. Prolonged NPO intervals are usually unnecessary and can lead to hypovolemia and patient dissatisfaction [19]. Data derived from enhanced recovery for colorectal surgery showed that complex carbohydrate (i.e., maltodextrin) loading the evening before and 2-3 $\mathrm{h}$ prior to anesthesia with a non-particulate drink can minimize the metabolic stress response, improve postoperative insulin resistance, and lower protein breakdown [20]. This may be omitted for diabetic mothers due to potential for delayed gastric emptying and hyperglycemia. The SOAP ERAC protocol suggests 16 ounces $(\sim 500 \mathrm{~mL})$ of clear apple juice $2 \mathrm{~h}$ prior to scheduled cesareans as an easy, acceptable choice [21].

\section{Intraoperative Elements}

Multimodal analgesia has become a key component for most surgeries/anesthetics and all enhanced recovery protocols involving medications and techniques beyond routine surgical anesthesia. Analgesic medications may be administered immediately preop, intraop, and continued postoperative. Nonopioid analgesics and techniques are utilized to minimize opioid consumption. However, ERAC goes beyond analgesics (see Table 1).

The intraoperative components of ERAC include start of scheduled acetaminophen (may start preoperatively), NSAIDs, limiting the amount of neuraxial opioid (i.e., morphine), prevention of hypothermia and nausea, and supporting mother-infant bonding, among others [9*0]. The routine use of prophylactic vasopressor infusions (e.g., phenylephrine $0.5-1$ $\mathrm{mcg} / \mathrm{kg} / \mathrm{min}$ ) helps to reduce hypotension induced nausea following spinal anesthesia. Two different classes of prophylactic antiemetics should be used (e.g., 5HT3 antagonist ondansetron, glucocorticoid dexamethasone, and/or D2 receptor antagonist metoclopramide). The suggested doses of neuraxial morphine for cesarean are 1-3 mg epidural or 50-150 mcg intrathecal (IT) to limit opioid side effects. Scheduled acetaminophen $1000 \mathrm{mg}$ (TID or QID) starting preop or intraop and NSAIDs (e.g., ketorolac $30 \mathrm{mg}$ IV after peritoneal closure, followed by either ketorolac (15-30 mg) Q6h, ibuprofen $600 \mathrm{mg}$ Q6h, or naproxen $500 \mathrm{mg}$ Q12h (see Table 2). Prewarming patients before surgery helps to reduce intraoperative hypothermia; intraoperative warming measures are required, including keeping the $\mathrm{OR}>72{ }^{\circ} \mathrm{F} / 23^{\circ} \mathrm{C}[9 \bullet \bullet]$. The maximum acetaminophen dose is $4000 \mathrm{mg} / 24 \mathrm{~h}$, as per FDA approval [22].

\section{Multimodal Analgesia}

Multimodal analgesia may involve regional blocks or wound infusion of local anesthetics and multiple non-opioid analgesics to modify or decrease neuronal transmission of pain, alter physiologic responses to painful stimuli, and reduce opioid consumption, decreasing the potential for postoperative opioid tolerance and development of persistent opioid use.

\section{Gabapentinoids}

Gabapentinoids (i.e., gabapentin and pregabalin) bind to and block the $\alpha_{2} \delta$ subunit containing voltage-depending calcium channel and may be effective in reducing postoperative pain. One meta-analysis of non-cesarean patients found gabapentin doses of $900 \mathrm{mg}$ and $1200 \mathrm{mg}$ or pregabalin $150 \mathrm{mg}$ and $300 \mathrm{mg}$ decreased postop opioid use and pain scores [23]. Gabapentin before and for 2 days post-CD decreased pain 
Table 1 Key components of enhanced recovery after cesarean

\begin{tabular}{|c|c|c|}
\hline Preoperative & Intraoperative & Postoperative \\
\hline $\begin{array}{l}\text { - Patient education } \\
\text { - Limited fasting } \\
\text { interval } \\
\text { - Carbohydrate } \\
\text { loading }\end{array}$ & $\begin{array}{l}\text { - Prevent and treat spinal iduced hypotension } \\
\text { - Maintain normothermia } \\
\text { - Intra- and postop nausea and vomiting } \\
\text { prophylaxis } \\
\text { - Optimal uterotonic administration } \\
\text { - Multimodal analgesia } \\
\text { - Promote breastfeeding and maternal-infant } \\
\text { bonding }\end{array}$ & $\begin{array}{l}\text { - Early oral intake } \\
\text { - Early mobilization } \\
\text { - Promote resting periods } \\
\text { - Early urinary catheter removal } \\
\text { - Venous thromboembolism } \\
\text { prophylaxis } \\
\text { - Continue multimodal analgesia } \\
\text { - Breastfeeding support } \\
\text { - Promote return of bowel function }\end{array}$ \\
\hline
\end{tabular}

Key components of an enhanced recovery after cesarean protocol, modified from Society for Obstetric Anesthesia and Perinatology Consensus, Anesthesia Analgesia 2020, with permission slightly (4.0 vs 4.7 VAS, $P<.05)$ on movement at $24 \mathrm{~h}$, however with no difference in opiate use or persistent pain scores [24]. A recent meta-analysis found that gabapentinoids were associated with lower postoperative pain intensity, but the difference was not clinically significant $(\leq 1 \mathrm{VAS})$ and associated with more frequent side effects of dizziness and visual disturbances [25•]. Gabapentinoids, while not currently recommended for routine ERAC, may benefit high-risk parturients such as those with chronic pain, opioid use disorders.

\section{Regional Blocks for Cesarean Surgery}

Regional blocks useful for cesarean surgery include truncal blocks (TAP, QL) or wound infusion. Overall, these have not been shown to have significant improvement when used in addition to the triad of neuraxial morphine and scheduled acetaminophen and NSAID [9••]. Regional blocks are useful when neuraxial morphine cannot be given, as a rescue technique for severe pain, or for patients at high risk for severe pain $[26 \bullet \bullet$.

\section{Transversus Abdominus Plane Block}

TAP blocks have been studied for CD but do not provide a routine benefit in addition to neuraxial opioids, except following general anesthesia or when neuraxial opioids need to be omitted [9••]. Posterior or lateral TAP block for cesarean did not confer additional benefits; results are similar to wound infiltration and inferior when compared with IT morphine [27]. Surgical infiltration of the abdominus plane may provide similar results [27].

\section{Quadratus Lumborum Blocks}

Many studies have examined the effectiveness of quadratus lumborum (QL) blocks in decreasing post abdominal surgery
Table 2 Key medication examples enhanced recovery after cesarean

\begin{tabular}{|c|c|c|}
\hline Preoperative & Intraoperative & Postoperative \\
\hline $\begin{array}{l}\text { Carbohydrate load } 2 \text { h preop: } \\
\text { - Clear apple juice } 500 \mathrm{ml} \\
\text { Multimodal analgesia: } \\
\text { - Acetaminophen } 1 \mathrm{~g} \text { PO }\end{array}$ & $\begin{array}{l}\text { Neuraxial morphine: } \\
\cdot \leq 3 \mathrm{mg} \text { epidural or } \\
\cdot \leq 150 \mathrm{mcg} \text { IT } \\
\text { Nausea Prophylaxis } \geq 2 \text { agents: } \\
\text { - } 4 \mathrm{mg} \text { ondansetron, } \\
\text { - } 10 \mathrm{mg} \text { metoclopramide, } \\
\text { - } 4 \mathrm{mg} \text { dexamethasone } \\
\text { Prevent hypotension: } \\
\text { - Phenylephrine infusion } 0.5 \\
\text { mcg/kg/min initial, titrate } \\
\text { Multimodal analgesia: } \\
\text { - Ketorolac } 30 \text {-mg IV after } \\
\text { peritoneal closure }\end{array}$ & $\begin{array}{l}\text { Multimodal analgesia: } \\
\text { - Acetaminophen } 1 \mathrm{~g} \text { PO Q6h } \\
\text { NSAID, choice of: } \\
\text { - Ketorolac } 30 \mathrm{mg} \text { IV Q6h or } \\
\text { - Ibuprofen } 600 \mathrm{mg} \text { POQ6h or } \\
\text { - Naproxen } 500 \mathrm{mg} \text { PO Q12h } \\
\text { Opioid as PRN only: } \\
\text { - Oxycodone } 5 \mathrm{mg} \text { PO PRN }\end{array}$ \\
\hline
\end{tabular}

Key medication examples for enhanced recovery after cesarean of low-risk patients, by phase of care. May give first dose of acetaminophen intraoperative or in PACU if did not receive prior to surgery

$P O$ Per os, $I T$ intrathecal, $I V$ intravenous, $P R N$ as needed, $Q$ every 
pain. The anterior QL (QL1) block acts like a TAP block while a posterior QL (QL2) block may spread local anesthetic more medially towards the paravertrebral spaces and inhibit visceral pain in addition to somatic pain [28]. QL block decreased intraoperative and postoperative opioid consumption in patients compared with TAP blocks for abdominal hysterectomies under general anesthesia [29]. In the absence of IT morphine, cesarean patients randomized to QL2 blocks had less postoperative morphine use than the TAP block group [30], and lower morphine usage and VAS pain scores [28]. However, adding QL blocks to patients receiving neuraxial morphine did not significantly change pain scores or reduce opioid consumption. QL2 block did not improve pain scores above IT morphine and scheduled non-opioid analgesics for $\mathrm{CD}[31 \bullet]$

\section{Local Anesthetic Wound Infusions}

Continuous wound infusions have been used to help control postoperative pain in cesarean delivery and were superior to epidural morphine $2 \mathrm{mg}$ every $12 \mathrm{~h}$ with scheduled acetaminophen and diclofenac only as a rescue [32]. In cesarean patients receiving $150 \mathrm{mcg}$ morphine IT with scheduled acetaminophen and systemic ketorolac/ibuprofen, the addition of a continuous wound infusion of ropivacaine $0.2 \%$ with ketorolac $30 \mathrm{mg} / 48 \mathrm{~h}$ had no statistically significant difference in pain scores up to $48 \mathrm{~h}$, patient satisfaction, opioid use, or postpartum depression [33]. The difference in the benefit of continuous wound infusion between these two studies is most likely due to the absence of scheduled systemic NSAID in the first study. Most studies have not found a benefit of peripheral local anesthetic nerve blocks in addition to the triad of neuraxial morphine and scheduled non-opioid analgesics of both acetaminophen and NSAID [9••, 34].

\section{Liposomal Bupivacaine}

Liposomal formulations provide slow release and thus prolonged effect of a local anesthetic. However, results with liposomal bupivacaine in cesarean delivery have been mixed. A retrospective study found incisional liposomal bupivacaine reduced MMEQ [35]. A prospective study of liposomal bupivacaine in the $\mathrm{CD}$ incision did not find significantly reduced pain scores or MMEQ in the first $48 \mathrm{~h}$ [34]. A recent study funded by the manufacturer showed liposomal bupivacaine $266 \mathrm{mg}$ plus bupivacaine $50 \mathrm{mg}$ in TAP block reduced 72-h opioid consumption of $-16.5 \mathrm{mg}, P=0.012$, and had more opioid-spared patients $(54 \%$ vs $25 \%, P=0.001$ ) compared with bupivacaine $50 \mathrm{mg}$ alone [36]. However, $6 \%$ of TAP blocks were incorrectly placed on review, and when all treated patients were included in analysis, there was no significant difference in opioid consumption between groups. The additional of intrathecal morphine to liposomal bupivacaine TAP block significantly reduced MMEQ in the first $24 \mathrm{~h}$ after $\mathrm{CD}$, but there were no differences in opioid use in the 24-72-h time period, suggesting a lack of prolonged benefit [37]. A recent meta-analysis found perineural liposomal bupivacaine did not provide a clinically important benefit using area under the curve pain scores $24-72 \mathrm{~h}$ after injection or in any of the secondary outcomes of pain at rest, time to first analgesic request, or opioid consumption up to $72 \mathrm{~h}$ [38]. Regarding the efficacy of liposomal bupivacaine, another recent article and editorial noted a high risk of study bias in $84 \%$ of articles showing significant benefits of liposomal bupivacaine and primary study outcomes, compared with only $14 \%$ of articles with a low risk of study bias [39, 40॰].

\section{NMDA Antagonists}

NMDA receptor antagonists are potential analgesics that prevent central sensitization and development of chronic pain [41]. Note that the prevention of neuropathic pain and treatment of acute pain may involve different mechanisms. Opioids may produce hyperalgesia in a dose and time exposure-dependent fashion via NMDA receptor stimulation [14].

\section{Ketamine}

Ketamine, an NMDA receptor antagonist, has analgesia effect and has been used for prevention of acute and chronic pain, hyperalgesia, and central sensitization and may prevent acute opioid tolerance [12•, 42]. S-Ketamine (dose of $0.5 \mathrm{mg} / \mathrm{kg} \mathrm{IM}$ followed by $2 \mathrm{mcg} / \mathrm{kg} / \mathrm{min}$ IV infusion for $12 \mathrm{~h}$ ) significantly decreased morphine consumption after $\mathrm{CD}$ starting at $8 \mathrm{~h}$ and by $31 \%$ over $24 \mathrm{~h}$, increased time to first morphine use, and trended to reduced hyperalgesia at T10 [43].

\section{Magnesium}

Perioperative magnesium, which also has NMDA antagonist effects, reduced pain scores at $24 \mathrm{~h}$ in a meta-analysis of nonobstetric patients and may reduce analgesic consumption in obstetric patients [44]. Magnesium 50-mg/kg decreased pain scores and medication use after general anesthesia for cesarean $[45,46]$. However, a 2006 study with magnesium 50 $\mathrm{mg} / \mathrm{kg}$ load with $2 \mathrm{~g} / \mathrm{h}, 25 \mathrm{mg} / \mathrm{kg}$ load with $1 \mathrm{~g} / \mathrm{h}$, or placebo started $1 \mathrm{~h}$ prior to cesarean under neuraxial anesthesia did not find a difference in pain severity [47]. A 2017 systematic review found magnesium decreased analgesic requirements and lowered VAS scores after CD [48].

\section{Dextromethorphan}

Dextromethorphan, a non-competitive NMDA antagonist, may decrease both sites of injury pain (primary site) and 
outside the injury (secondary site) hyperalgesia that can develop from surgery or trauma [41]. Low dose $(30 \mathrm{mg})$ dextromethorphan provided significant anti-hyperalgesic effects in humans for primary and secondary hyperalgesia and decreases peripheral and central neuronal sensitization in a freeze-injury pain model [49]. A meta-analysis of 21 studies of primarily general, gynecology, and orthopedic surgeries showed perioperative dextromethorphan significantly decreased opioid consumption by $10-\mathrm{mg}$ morphine equivalents and pain scores by almost 1 (10-point pain scale) through $24 \mathrm{~h}$ [50]. However, dextromethorphan has not been studied specifically for cesarean; usage in high-risk women may be considered.

\section{Alpha-2 Adrenergic Agonists}

The alpha2-adrenergic agonists clonidine and dexmedetomidine have analgesic properties, but the limited evidence for cesareans did not warrant their inclusion in ERAC protocols. However, they may be useful in high-risk patients for pain or tolerance to opioids. Clonidine $1.2 \mathrm{mcg} / \mathrm{ml} /$ bupivacaine $0.1 \%$ infused epidural postcesarean for $24 \mathrm{~h}$ provided good analgesia with no need for supplemental opioids for $70 \%$ of parturients with opioid use disorder on buprenorphine [44, 51]. Dexmedetomidine $4 \mathrm{mg}$ IT significantly decreased VAS scores during and immediately after $(2.1 \pm 1$ vs $3.6 \pm 1, P<0.001)$ cesarean surgery [52]. Dexmedetomidine as IV infusion of $0.2-1.4 \mathrm{mcg} / \mathrm{kg} / \mathrm{h}$ after a load of $1 \mathrm{mcg} / \mathrm{kg}$ may also be helpful [26••].

\section{Postoperative Elements}

Key postoperative elements of ERAC include early oral intake, early urinary catheter removal (6-12 h) and early mobilization out of bed and attempted ambulation within the first $24 \mathrm{~h}$.

\section{Early Oral Intake}

Early oral intake hastens return of bowel function, improves maternal satisfaction, and quickens time to ambulation and discharge without increasing complications such as nausea, vomiting, or infection. Parturients undergoing general anesthesia for cesarean delivery had faster return of bowel function and improved patient satisfaction with early oral feeding in a RCT [53]. Another RCT with general and neuraxial anesthesia patients found faster time to ambulation and earlier discharge in the early feeding cohort following cesarean [54]. Lastly, a Cochrane review found that gum chewing in PACU expedited return of bowel function and decreased length of stay, albeit with low grade evidence [55]. These studies also found no difference in postoperative complications, nausea, and bloating in the early feeding groups.

\section{Special Considerations}

\section{Postop Opioid Use}

ERAC implementations lowered opioid usage with no significant change in postop complication rates, pain scores, or readmission rates. Reduction of opioid consumption can be especially important during the current opioid crisis. ERAC implementation led to a $40 \%$ lower morphine equivalent usage (60 mg vs $104 \mathrm{mg}$ ), fewer patients requiring opioids within $24 \mathrm{~h}$ of discharge $(41.1 \%$ vs $74.6 \%, P<$ 0.001 ), and no difference in pain scores during inpatient hospitalization [56]. ERAC reduced oxycodone consumption an average of $36 \mathrm{mg} /$ patient after cesarean delivery with no difference in pain scores throughout hospital admission [57]. Similarly, ERAC protocols significantly reduced opioid consumption $38 \%$ with lower pain scores (7 vs $8, P=0.007)$ and shorter $(2.5 \pm 0.5$ vs $2.9 \pm 1.2$ days, $P$ $<0.001)$ length of stay $[58 \cdot]$.

\section{Length of Stay/Cost Savings}

ERAC protocols reduce LOS and cost savings without increasing adverse events such as 30-day readmission rates. Hospitals have a large variation in LOS, with a median discharge of $47 \%$ of $C D$ patients within 2 days, with the earlier discharge group being slightly younger, history of prior CD, non-teaching hospital, and having fewer comorbidities [4]. While insurers are required to cover 4-day hospitalization for cesarean, early discharge is allowed if the patient and attending provider agree [59]. An RCT in New York City showed a significantly shorter LOS for women in the ERAC cohort, with the added benefits of increased breastfeeding rates, higher patient satisfaction [60]. In the UK, introduction of ERAC components over a 2-year period time significantly increased POD 1 discharge from 1.6 to $25 \%$ and reduced costs $[17 \bullet \bullet]$.

\section{Racial Disparities}

Racial and ethnic healthcare disparities exist in the USA not only for severe maternal morbidity and cesarean delivery rate [61] but also for the recognition and treatment of pain [16]. Severe pain $\geq 7$ VAS was more common in black and Hispanic women, and they were undertreated, receiving significantly fewer oxycodone tablets postpartum days 1 and 2 [62]. Black women have a longer LOS and higher $\mathrm{CD}$ rate [63]. Enhanced recovery implementation eliminated racial disparities in LOS with no differences in readmissions or mortality and improved outcomes of pneumonia and ileus following colorectal surgery [64•]. Implicit bias in healthcare professionals may contribute to differences in healthcare outcomes [65•]. Use of ERAS for 
cesarean delivery should reduce racial disparities by using standardized universal protocols [66].

\section{COVID-19}

The Coronavirus (COVID-19) pandemic impacted ERAC as well. NSAIDs are safe to use in COVID-19 patients [67]. COVID-19 may cause hypercoagulability, and VTE prophylaxis may need to be continued for 2-6 weeks [68]. The pandemic has accelerated patients' desire to leave the hospital earlier; our post-ERAC, and post-COVID-19 2-night LOS increased from 12 to $41 \%$, with no harm to mother or baby [69]. Patient expectations and desire to be discharged earlier have significantly decreased LOS during the pandemic.

\section{High-Risk Patients}

Substance Use Disorder The parturient with a history of substance use disorder may be more difficult to manage pain, especially after surgery. The standard ERAC template serves as an excellent starting point for overall care. In addition to the standard triad of neuraxial morphine, acetaminophen, and NSAID, further pharmacologic approaches may be helpful. Possibilities include postdelivery infusion of epidural local anesthetics/narcotics, alpha-2 adrenergic agonists, NMDA agonists, TAP/QL blocks, or use of gabapentinoids.

Perhaps one of the most important aspects of ERAC is reducing total opioid exposure and the potential for maternal opioid addiction. The risk of opioid naïve parturients becoming chronic opioid use disorder following cesarean was $1 / 300$ [70], representing public health issues affecting an estimated 4000 new mothers per year. Implementation of ERAC reduced morphine mg equivalents (MMEQ) by $40 \%$, from 46 to $28 \mathrm{mg}, P<0.001$, in addition to a decrease in peak pain scores by 1 VAS (from 8 to 7), $P<0.01$ [58•]. Lower inhospital opioids requirements led to a $35 \%$ reduction in opioid discharge prescribing [71]. States have enacted laws to limit opioid prescriptions, decreasing postcesarean discharge opioid prescription by 20 MMEQ [72]. Use of opioids for greater then 5 days increases chances for still using opioids 1 year later [73]. Thus, implementation of ERAC reduces in hospital opioid exposure and discharge opioids and should reduce the incidence of chronic opioid use following cesareans.

Opioid Use Disorder Patients with opioid use disorder should be continued on their normal medications (e.g., methadone, buprenorphine) plus extra modalities as discussed above [74]. Suggestions include stepwise multimodal analgesia with options of oral gabapentin 300-600 mg PO Q8h, ketamine 0.5 $\mathrm{mg} / \mathrm{kg}$ bolus, $2 \mathrm{mcg} / \mathrm{kg} / \mathrm{min}$ infusion, and/or dexmedetomidine infusion $0.2-1.5 \mathrm{mcg} / \mathrm{kg} / \mathrm{h}$ after load 1 $\mathrm{mcg} / \mathrm{kg} / 10-20 \min [26 \bullet \bullet, 51]$.

\section{Conclusion}

Enhanced recovery after cesarean provides evidenced-based standardized care for the perioperative period, with benefits for maternal pain relief, mobilization, improved maternalinfant bonding, decreased opioid and rescue medication consumption, and shorter length of stay. With patient engagement started preoperatively, ERAC goals can be achieved, and with greater potential for improvements in chronic opioid use after cesarean, adjustments for higher risk patients, and improvement in racial healthcare disparities. Perhaps the next evolution of ERAC will involve pharmacogenetic testing and certainly "personalized" analgesic management [75].

\section{Compliance with Ethical Standards}

Conflict of Interest The authors declare that they have no conflict of interest.

\section{References}

Papers of particular interest, published recently, have been highlighted as:

- Of importance

•• Of major importance

1. Births. www.cdc.gov/nchs/nvss/births.html2020 Contract No.: September 1.

2. Births and Deaths. https://ourworldindata.org/births-anddeaths2020.

3. Lavand'homme P. Postpartum chronic pain. Minerva Anestesiol. 2019;85(3):320-4. https://doi.org/10.23736/S0375-9393.18. 13060-4.

4. Federspiel JJ, Suresh SC, Darwin KC, Szymanski LM. Hospitalization duration following uncomplicated cesarean delivery: predictors, facility variation, and outcomes. AJP Rep. 2020;10(2):e187-e97. https://doi.org/10.1055/s-0040-1709681.

5. Weibel S, Neubert K, Jelting Y, Meissner W, Wockel A, Roewer $\mathrm{N}$, et al. Incidence and severity of chronic pain after caesarean section: a systematic review with meta-analysis. Eur J Anaesthesiol. 2016;33(11):853-65. https://doi.org/10.1097/ EJA.0000000000000535.

6. Jin J, Peng L, Chen Q, Zhang D, Ren L, Qin P, et al. Prevalence and risk factors for chronic pain following cesarean section: a prospective study. BMC Anesthesiol. 2016;16(1):99. https://doi.org/10. 1186/s12871-016-0270-6.

7. Main EK, Goffman D, Scavone BM, Low LK, Bingham D, Fontaine PL, et al. National Partnership for Maternal Safety: consensus bundle on obstetric hemorrhage. Anesth Analg. 2015;121(1):142-8. https://doi.org/10.1097/AOG. 0000000000000869 .

8. Mann S, Pratt S, Gluck P, Nielsen P, Risser D, Greenberg P, et al. Assessing quality obstetrical care: development of standardized measures. Jt Comm J Qual Patient Saf. 2006;32(9):497-505. https://doi.org/10.1016/s1553-7250(06)32065-x.

9.• Bollag L, Lim G, Sultan P, Habib AS, Landau R, Zakowski M, et al. Society for Obstetric Anesthesia and Perinatology: consensus 
statement and recommendations for enhanced recovery after cesarean. Anesth Analg. 2020. https://doi.org/10.1213/ANE. 0000000000005257 This paper contains the SOAP consensus statement for enhanced recovery after cesarean, providing levels of evidence and strength of recommendation with detailed analgesic regimens for neuraxial opioids and nonopioid analgesics, with comments about each recommendation.

10. Zelaya CE, Dahlhamer JM, Lucas JW, Connor EM. Chronic pain and high-impact chronic pain among U.S. adults. NCHS Data Brief. 2019;2020(390):1-8.

11.• Eisenach JC, Pan PH, Smiley R, Lavand'homme P, Landau R, Houle TT. Severity of acute pain after childbirth, but not type of delivery, predicts persistent pain and postpartum depression. Pain. 2008;140(1):87-94. https://doi.org/10.1016/j.pain.2008.07.011 Landmark study that pain after cesarean delivery was associated with an increased risk of persistent pain or postpartum depression. Women with severe acute pain postpartum were $2.5 \times$ more likely to have persistent pain and $3 \times$ more likely to have postpartum depression than those with mild postpartum pain.

12. Komatsu R, Ando K, Flood PD. Factors associated with persistent pain after childbirth: a narrative review. Br J Anaesth. 2020;124(3): e117-e30. https://doi.org/10.1016/j.bja.2019.12.037 Persistent incisional pain following cesarean was associated with a coexisting chronic pain problem in another body part and severe acute post-op pain. Prepregnancy or pregnancy related back pain and heavier weight were associated with chronic back pain after pregnancy. These high-risk patients may benefit from adjuvants to ERAC protocols to reduce the risk of persistent pain.

13. Babazade R, Vadhera RB, Krishnamurthy P, Varma A, Doulatram G, Saade GR, et al. Acute postcesarean pain is associated with inhospital exclusive breastfeeding, length of stay and post-partum depression. J Clin Anesth. 2020;62:109697. https://doi.org/10. 1016/j.jclinane.2019.109697.

14. Richebe P, Capdevila X, Rivat C. Persistent postsurgical pain: pathophysiology and preventative pharmacologic considerations. Anesthesiology. 2018;129(3):590-607. https://doi.org/10.1097/ ALN.0000000000002238.

15. Wang LZ, Wei CN, Xiao F, Chang XY, Zhang YF. Incidence and risk factors for chronic pain after elective caesarean delivery under spinal anaesthesia in a Chinese cohort: a prospective study. Int $\mathrm{J}$ Obstet Anesth. 2018;34:21-7. https://doi.org/10.1016/j.ijoa.2018. 01.009 .

16. Hoffman KM, Trawalter S, Axt JR, Oliver MN. Racial bias in pain assessment and treatment recommendations, and false beliefs about biological differences between blacks and whites. Proc Natl Acad Sci U S A. 2016;113(16):4296-301. https://doi.org/10.1073/pnas. 1516047113

17.• Wrench IJ, Allison A, Galimberti A, Radley S, Wilson MJ. Introduction of enhanced recovery for elective caesarean section enabling next day discharge: a tertiary centre experience. Int $\mathrm{J}$ Obstet Anesth. 2015;24(2):124-30. https://doi.org/10.1016/j.ijoa. 2015.01.003 Landmark study showing the benefits of enhanced recovery after cesarean on length of stay and the importance of preoperative education in increasing patients' acceptance of earlier discharge even before implementation of other ERAC recommendations.

18. Prabhu M, McQuaid-Hanson E, Hopp S, Burns SM, Leffert LR, Landau R, et al. A shared decision-making intervention to guide opioid prescribing after cesarean delivery. Obstet Gynecol. 2017;130(1):42-6. https://doi.org/10.1097/AOG. 0000000000002094 .

19. Practice guidelines for preoperative fasting and the use of pharmacologic agents to reduce the risk of pulmonary aspiration: application to healthy patients undergoing elective procedures: an updated report by the American Society of Anesthesiologists Task Force on preoperative fasting and the use of pharmacologic agents to reduce the risk of pulmonary aspiration. Anesthesiology. 2017;126(3):37693. https://doi.org/10.1097/ALN.0000000000001452.

20. Gustafsson UO, Scott MJ, Hubner M, Nygren J, Demartines N, Francis N, et al. Guidelines for perioperative care in elective colorectal surgery: Enhanced Recovery After Surgery (ERAS((R))) Society Recommendations: 2018. World J Surg. 2019;43(3):65995. https://doi.org/10.1007/s00268-018-4844-y.

21. Enhanced recovery after cesarean (ERAC) consensus statement. Soc Obstetr Anesth Perinatol. 2019. www.soap.org. Accessed 16 Sept 2020.

22. FDA. Acetaminophen information. Food Drug Admin. 2017. https://www.fda.gov/drugs/information-drug-class/ acetaminophen-information.

23. Hu J, Huang D, Li M, Wu C, Zhang J. Effects of a single dose of preoperative pregabalin and gabapentin for acute postoperative pain: a network meta-analysis of randomized controlled trials. J Pain Res. 2018;11:2633-43. https://doi.org/10.2147/JPR.S170810.

24. Monks DT, Hoppe DW, Downey K, Shah V, Bernstein P, Carvalho JC. A perioperative course of gabapentin does not produce a clinically meaningful improvement in analgesia after cesarean delivery: a randomized controlled trial. Anesthesiology. 2015;123(2):320-6. https://doi.org/10.1097/ALN.0000000000000722.

25. Verret M, Lauzier F, Zarychanski R, Perron C, Savard X, Pinard AM, et al. Perioperative use of gabapentinoids for the management of postoperative acute pain: a systematic review and meta-analysis. Anesthesiology. 2020;133(2):265-79. https://doi.org/10.1097/ ALN.0000000000003428 Major review article of perioperative gabapentinoids did not lower pain scores in a clinically significant way and was associated with more side effects. This review did not suggest their routine use perioperatively.

26.• Landau R. Post-cesarean delivery pain. Management of the opioiddependent patient before, during and after cesarean delivery. Int J Obstet Anesth. 2019;39:105-16. https://doi.org/10.1016/j.ijoa. 2019.01.011 For opioid dependent peri-partum patients, the baseline total daily opioid medication-assisted treatments should be maintained. A CSE with intrathecal morphine should be considered for cesarean so the epidural can be used for postoperative analgesia for up to $72 \mathrm{~h}$. Adjuvants may be used and include clonidine, gabapentin, ketamine, dexmedetomidine and/or truncal blocks.

27. Tran DQ, Bravo D, Leurcharusmee P, Neal JM. Transversus abdominis plane block: a narrative review. Anesthesiology. 2019;131(5):1166-90. https://doi.org/10.1097/ALN. 0000000000002842 .

28. Blanco R, Ansari T, Girgis E. Quadratus lumborum block for postoperative pain after caesarean section: a randomised controlled trial. Eur J Anaesthesiol. 2015;32(11):812-8. https://doi.org/10.1097/ EJA.0000000000000299.

29. Yousef NK. Quadratus lumborum block versus transversus abdominis plane block in patients undergoing total abdominal hysterectomy: a randomized prospective controlled trial. Anesth Essays Res. 2018;12(3):742-7. https://doi.org/10.4103/aer.AER 10818.

30. Blanco R, Ansari T, Riad W, Shetty N. Quadratus lumborum block versus transversus abdominis plane block for postoperative pain after cesarean delivery: a randomized controlled trial. Reg Anesth Pain Med. 2016;41(6):757-62. https://doi.org/10.1097/AAP. 0000000000000495.

31. Tamura T, Yokota S, Ando M, Kubo Y, Nishiwaki K. A tripleblinded randomized trial comparing spinal morphine with posterior quadratus lumborum block after cesarean section. Int J Obstet Anesth. 2019;40:32-8. https://doi.org/10.1016/j.ijoa.2019.06.008 Compared QL block to sham QL in cesarean patients receiving intrathecal morphine, and in a subgroup without 
intrathecal morphine. It found no pain benefits to QL blocks in both intrathecal morphine and no intrathecal morphine groups.

32. O'Neill P, Duarte F, Ribeiro I, Centeno MJ, Moreira J. Ropivacaine continuous wound infusion versus epidural morphine for postoperative analgesia after cesarean delivery: a randomized controlled trial. Anesth Analg. 2012;114(1):179-85. https://doi.org/10.1213/ ANE.0b013e3182368e87.

33. Barney EZ, Pedro CD, Gamez BH, Fuller ME, Dominguez JE, Habib AS. Ropivacaine and ketorolac wound infusion for postcesarean delivery analgesia: a randomized controlled trial. Obstet Gynecol. 2020;135(2):427-35. https://doi.org/10.1097/AOG. 0000000000003601.

34. Prabhu M, Clapp MA, McQuaid-Hanson E, Ona S, O'Donnell T, James K, et al. Liposomal bupivacaine block at the time of cesarean delivery to decrease postoperative pain: a randomized controlled trial. Obstet Gynecol. 2018;132(1):70-8. https://doi.org/10.1097/ AOG.0000000000002649.

35. Parikh P, Sunesara I, Singh Multani S, Patterson B, Lutz E, Martin JN Jr. Intra-incisional liposomal bupivacaine and its impact on postcesarean analgesia: a retrospective study. J Matern Fetal Neonatal Med. 2019;32(6):966-70. https://doi.org/10.1080/ 14767058.2017.1397118.

36. Nedeljkovic SS, Kett A, Vallejo MC, Horn JL, Carvalho B, Bao X, et al. Transversus abdominis plane block with liposomal bupivacaine for pain after cesarean delivery in a multicenter, randomized, double-blind, controlled trial. Anesth Analg. 2020;131(6):1830-9. https://doi.org/10.1213/ANE. 0000000000005075 .

37. Hutchins JL, Renfro L, Orza F, Honl C, Navare S, Berg AA. The addition of intrathecal morphine to a transversus abdominis plane block with liposome bupivacaine provides more effective analgesia than transversus abdominis plane block with liposome bupivacaine alone: a retrospective study. Local Reg Anesth. 2019;12:7-13. https://doi.org/10.2147/LRA.S190225.

38. Hussain N, Brull R, Sheehy BT, Kushelev M, Essandoh MK, Abdallah FW. The mornings after-periarticular liposomal bupivacaine infiltration does not improve analgesic outcomes beyond 24 hours following total knee arthroplasty: a systematic review and meta-analysis. Reg Anesth Pain Med. 2021;46(1):61-72. https://doi.org/10.1136/rapm-2020-101995.

39. Ilfeld BM, Eisenach JC, Gabriel RA. Clinical effectiveness of liposomal bupivacaine administered by infiltration or peripheral nerve block to treat postoperative pain. Anesthesiology. 2021;134(2): 283-344. https://doi.org/10.1097/ALN.0000000000003630.

40. McCann ME. Liposomal Bupivacaine. Anesthesiology. 2021;134(2):139-42. https://doi.org/10.1097/ALN. 0000000000003658 Editorial discussing liposomal bupivcaine is not superior to bupivaciane for post-operative analgesia.

41. Raja SN, Sivanesan E, Guan Y. Central sensitization, N-methyl-Daspartate receptors, and human experimental pain models: bridging the gap between target discovery and drug development. Anesthesiology. 2019;131(2):233-5. https://doi.org/10.1097/ ALN.0000000000002808.

42. Mao J, Price DD, Mayer DJ. Mechanisms of hyperalgesia and morphine tolerance: a current view of their possible interactions. Pain. 1995;62(3):259-74. https://doi.org/10.1016/0304-3959(95)000732.

43. Suppa E, Valente A, Catarci S, Zanfini BA, Draisci G. A study of low-dose S-ketamine infusion as "preventive" pain treatment for cesarean section with spinal anesthesia: benefits and side effects. Minerva Anestesiol. 2012;78(7):774-81.

44. Soens MA, He J, Bateman BT. Anesthesia considerations and postoperative pain management in pregnant women with chronic opioid use. Semin Perinatol. 2019;43(3):149-61. https://doi.org/10.1053/j. semperi.2019.01.004.
45. Rezae M, Naghibi K, Taefnia AM. Effect of pre-emptive magnesium sulfate infusion on the post-operative pain relief after elective cesarean section. Adv Biomed Res. 2014;3:164. https://doi.org/10. 4103/2277-9175.139127.

46. Mireskandari SM, Pestei K, Hajipour A, Jafarzadeh A, Samadi S, Nabavian O. Effects of preoperative magnesium sulphate on postcesarean pain, a placebo controlled double blind study. J Family Reprod Health. 2015;9(1):29-33.

47. Paech MJ, Magann EF, Doherty DA, Verity LJ, Newnham JP. Does magnesium sulfate reduce the short- and long-term requirements for pain relief after caesarean delivery? A double-blind placebo-controlled trial. Am J Obstet Gynecol. 2006;194(6):1596602; discussion 602-3. https://doi.org/10.1016/j.ajog.2006.01.009.

48. McKeown A, Seppi V, Hodgson R. Intravenous magnesium sulphate for analgesia after caesarean section: a systematic review. Anesthesiol Res Pract. 2017;2017:9186374-9. https://doi.org/10. 1155/2017/9186374.

49. Martin E, Narjoz C, Decleves X, Labat L, Lambert C, Loriot MA, et al. Dextromethorphan analgesia in a human experimental model of hyperalgesia. Anesthesiology. 2019;131(2):356-68. https://doi. org/10.1097/ALN.0000000000002736.

50. King MR, Ladha KS, Gelineau AM, Anderson TA. Perioperative dextromethorphan as an adjunct for postoperative pain: a metaanalysis of randomized controlled trials. Anesthesiology. 2016;124(3):696-705. https://doi.org/10.1097/ALN. 0000000000000950 .

51. Hoyt MR, Shah U, Cooley J, Temple M. Use of epidural clonidine for the management of analgesia in the opioid addicted parturient on buprenorphine maintenance therapy: an observational study. Int $\mathrm{J}$ Obstet Anesth. 2018;34:67-72. https://doi.org/10.1016/j.ijoa.2018. 01.001.

52. Kong D, Bai J, Ma S, Li C, Yang L, Kong X. Effects of dexmedetomidine hydrochloride on hemodynamics, postoperative analgesia and cognition in cesarean section. Exp Ther Med. 2018;16(3):1778-83. https://doi.org/10.3892/etm.2018.6363.

53. Mawson AL, Bumrungphuet S, Manonai J. A randomized controlled trial comparing early versus late oral feeding after cesarean section under regional anesthesia. Int J Womens Health. 2019;11: 519-25. https://doi.org/10.2147/IJWH.S222922.

54. Aydin Y, Altunyurt S, Oge T, Sahin F. Early versus delayed oral feeding after cesarean delivery under different anesthetic methodsa randomized controlled trial anesthesia, feeding in cesarean delivery. Ginekol Pol. 2014;85(11):815-22. https://doi.org/10.17772/ gp/1906.

55. Pereira Gomes Morais E, Riera R, Porfirio GJ, Macedo CR, Sarmento Vasconcelos V, de Souza Pedrosa A, et al. Chewing gum for enhancing early recovery of bowel function after caesarean section. Cochrane Database Syst Rev. 2016;10:CD011562. https:// doi.org/10.1002/14651858.CD011562.pub2.

56. Lester SA, Kim B, Tubinis MD, Morgan CJ, Powell MF. Impact of an enhanced recovery program for cesarean delivery on postoperative opioid use. Int J Obstet Anesth. 2020;43:47-55. https://doi.org/ 10.1016/j.ijoa.2020.01.005.

57. Shinnick JK, Ruhotina M, Has P, Kelly BJ, Brousseau EC, O'Brien $\mathrm{J}$, et al. Enhanced recovery after surgery for cesarean delivery decreases length of hospital stay and opioid consumption: a quality improvement initiative. Am J Perinatol. 2020. https://doi.org/10. 1055/s-0040-1709456.

58. Kleiman AM, Chisholm CA, Dixon AJ, Sariosek BM, Thiele RH, Hedrick TL, et al. Evaluation of the impact of enhanced recovery after surgery protocol implementation on maternal outcomes following elective cesarean delivery. Int J Obstet Anesth. 2020;43:39 46. https://doi.org/10.1016/j.ijoa.2019.08.004 Enhanced recovery protocols reduced post-cesarean opioid use by $38 \%$ and increased POD 3 discharge from $49 \%$ to $71 \%$ without a change in 30- day readmission rate. 
59. Maternity Length of Stay. Rules. National Conference. of State Legislatures. 2018. www.ncsl.org/research/health/final-maternitylength-of-stay-rules-published.aspx. Accessed 26 Nov 2020.

60. Teigen NC, Sahasrabudhe N, Doulaveris G, Xie X, Negassa A, Bernstein J, et al. Enhanced recovery after surgery at cesarean delivery to reduce postoperative length of stay: a randomized controlled trial. Am J Obstet Gynecol. 2020;222(4):372.e1-372.e10. https://doi.org/10.1016/j.ajog.2019.10.009.

61. Admon LK, Winkelman TNA, Zivin K, Terplan M, Mhyre JM, Dalton VK. Racial and ethnic disparities in the incidence of severe maternal morbidity in the United States, 2012-2015. Obstet Gynecol. 2018;132(5):1158-66. https://doi.org/10.1097/AOG. 0000000000002937.

62. Johnson JD, Asiodu IV, McKenzie CP, Tucker C, Tully KP, Bryant $\mathrm{K}$, et al. Racial and ethnic inequities in postpartum pain evaluation and management. Obstet Gynecol. 2019;134(6):1155-62. https:// doi.org/10.1097/AOG.0000000000003505.

63. Tangel V, White RS, Nachamie AS, Pick JS. Racial and ethnic disparities in maternal outcomes and the disadvantage of peripartum Black women: a multistate analysis, 2007-2014. Am J Perinatol. 2019;36(8):835-48. https://doi.org/10.1055/s-00381675207.

64. Wahl TS, Goss LE, Morris MS, Gullick AA, Richman JS, Kennedy GD, et al. Enhanced Recovery After Surgery (ERAS) eliminates racial disparities in postoperative length of stay after colorectal surgery. Ann Surg. 2018;268(6):1026-35. https://doi.org/10.1097/ SLA.0000000000002307 Enhanced recovery protocols eliminated LOS differences between Black and Caucasian patients with colorectal surgery and lowered LOS for both groups overall without affecting 30-day readmission rates, morbidity, or mortality.

65. Hall WJ, Chapman MV, Lee KM, Merino YM, Thomas TW, Payne BK, et al. Implicit racial/ethnic bias among health care professionals and its influence on health care outcomes: a systematic review. Am J Public Health. 2015;105(12):e60-76. https://doi.org/ 10.2105/AJPH.2015.302903 Implicit racial and ethnic bias scores in healthcare professionals are similar to those in the general population and affect to treatment decisions, treatment adherence, and patient health outcomes. Most healthcare providers appear to have an implicit bias of positive attitudes towards white people and negative attitudes towards people of color. Enacting ERAC protocols may help reduce the effects of these biases.
66. White RS, Matthews KC, Tangel V, Abramovitz S. Enhanced Recovery After Surgery (ERAS) programs for cesarean delivery can potentially reduce healthcare and racial disparities. J Natl Med Assoc. 2019;111(4):464-5. https://doi.org/10.1016/j.jnma. 2019.02.001.

67. Interim Considerations for Obstetric Anesthesia Care related to COVID19. www.soap.org2020. March 27, 2020.

68. Di Renzo GC, Giardina I. Coronavirus disease 2019 in pregnancy: consider thromboembolic disorders and thromboprophylaxis. Am J Obstet Gynecol. 2020;223(1):135. https://doi.org/10.1016/j.ajog. 2020.04.017.

69. Greene NH, Kilpatrick SJ, Wong MS, Ozimek JA, Naqvi M. Impact of labor and delivery unit policy modifications on maternal and neonatal outcomes during the coronavirus disease 2019 pandemic. Am J Obstet Gynecol MFM. 2020;2(4):100234. https://doi. org/10.1016/j.ajogmf.2020.100234.

70. Bateman BT, Franklin JM, Bykov K, Avorn J, Shrank WH, Brennan TA, et al. Persistent opioid use following cesarean delivery: patterns and predictors among opioid-naive women. Am J Obstet Gynecol. 2016;215(3):353 el-e18. https://doi.org/10.1016/ j.ajog.2016.03.016.

71. Prabhu M, Dubois H, James K, Leffert LR, Riley LE, Bateman BT, et al. Implementation of a quality improvement initiative to decrease opioid prescribing after cesarean delivery. Obstet Gynecol. 2018;132(3):631-6. https://doi.org/10.1097/AOG. 0000000000002789 .

72. Potnuru PP, Patel SD, Birnbach DJ, Epstein RH, Dudaryk R. Effects of state law limiting postoperative opioid prescription in patients after cesarean delivery. Anesth Analg. 2020;Publish Ahead of Print. https://doi.org/10.1213/ANE.0000000000004993.

73. Shah A, Hayes CJ, Martin BC. Characteristics of initial prescription episodes and likelihood of long-term opioid use - United States, 2006-2015. MMWR Morb Mortal Wkly Rep. 2017;66(10):2659. https://doi.org/10.15585/mmwr.mm6610a1

74. Collaborative CMQC. Mother \& baby substance exposure Toolkit. 2020.

75. Carvalho B, Habib AS. Personalized analgesic management for cesarean delivery. Int J Obstet Anesth. 2019;40:91-100. https:// doi.org/10.1016/j.ijoa.2019.02.124.

Publisher's Note Springer Nature remains neutral with regard to jurisdictional claims in published maps and institutional affiliations. 